\title{
Fluorine gas coinjection as a solution for enhancing spatial resolution of time-of-flight secondary ion mass spectrometry and separating mass interference
}

\author{
Agnieszka Priebe*, Laszlo Pethö and Johann Michler
}

Empa, Swiss Federal Laboratories for Materials Science and Technology, Laboratory for Mechanics of Materials and Nanostructures, Feuerwerkerstrasse 39, CH-36o2 Thun, Switzerland

*Corresponding author: agnieszka.priebe@empa.ch

\section{Supporting Information}

Table S1. PVD conditions used for fabrication of $\mathrm{Cu} / \mathrm{Zr} / \mathrm{ZrCuAg}$ multilayer structure. (.docx file)

Figure S1. Experimental setup: a) a diagram of the multilayer sample structure, b) an SEM image of GIS location with respect to the sample surface. (.docx file)

Figure S2. SEM image presenting the subsequent steps of adjusting five FIB parameters. (.docx file)

Figure S3. SEM images of post-FIB-TOF-SIMS craters obtained at different FIB energies and currents. (.docx file)

Figure $\mathrm{S}_{4}$. Comparison of the sample components' depth profiles obtained without and with the presence of fluorine gas. (.docx file)

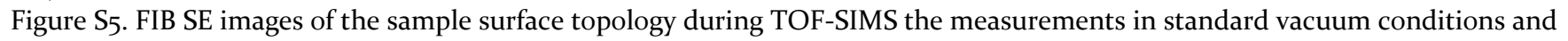
with the presence of fluorine gas. (.docx file)

Figure S6. Isotope abundance of $\mathrm{Cu}(\mathrm{a}), \mathrm{Zr}(\mathrm{b}), \mathrm{Ag}(\mathrm{c})$ and $\mathrm{Si}(\mathrm{d})$. (.docx file)

Figure $\mathrm{S}_{7}$. Comparison of $\mathrm{ZrO}$ and $\mathrm{ZrF}$ isotope abundance. (.docx file) 
Table S1. PVD conditions used for fabrication of $\mathrm{Cu} / \mathrm{Zr} / \mathrm{ZrCuAg}$ multilayer structure.

\begin{tabular}{|l|l|l|l|l|l|l|}
\hline Layer & Plasma voltage $[\mathrm{V}]$ & $\begin{array}{l}\text { Plasma current } \\
{[\mathrm{mA}]}\end{array}$ & $\begin{array}{l}\text { Deposition } \\
\text { time }[\mathrm{s}]\end{array}$ & $\begin{array}{l}\text { Argon flow } \\
{[\mathrm{sccm}]}\end{array}$ & $\begin{array}{l}\text { Process pressure } \\
{[\mathrm{mbar}]}\end{array}$ \\
\hline $\mathrm{Cu}$ & 460 & 200 & 1000 & 7 & $3 \times 10^{-3}$ \\
\hline $\mathrm{Zr}$ & 288 & 200 & 3440 & 10 & $4 \times 10^{-3}$ \\
\hline \multirow{3}{*}{$\mathrm{ZrCuAg}$} & $\mathrm{Zr}$ & 194 & 300 & & & \\
\cline { 2 - 8 } & $\mathrm{Cu}$ & 338 & 70 & 1890 & 15 & $5 \times 10^{-3}$ \\
\cline { 2 - 8 } & $\mathrm{Ag}$ & 331 & 17 & & & \\
\hline
\end{tabular}

a)

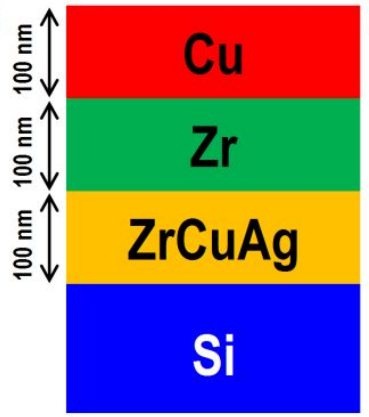

b) $500 \mu \mathrm{m}$

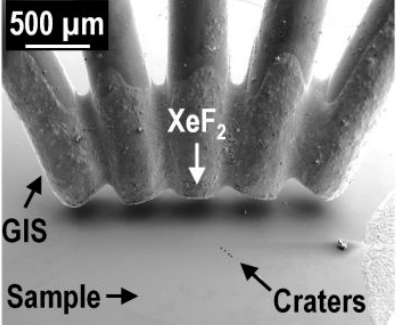

Ag connection

Figure S1. Experimental setup: a) a diagram of the multilayer sample structure, b) an SEM image of GIS location with respect to the sample surface.

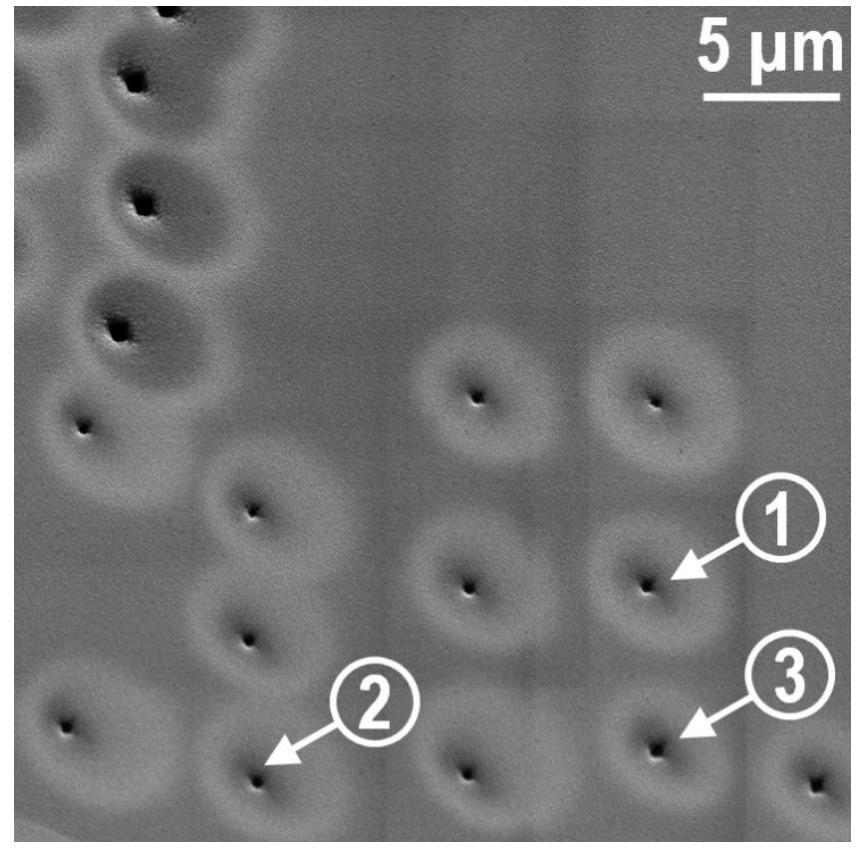

Figure S2. SEM image presenting the subsequent steps of adjusting five FIB parameters (i.e. the beam focus, $x$-stigmator, $y$ stigmator, $x$-beam centring and $y$-beam centring). 1 - the optimized milled dot size and shape (i.e. the dot pattern is round, stigmatism is reduced, a symmetrical halo is as small as possible; here the beam centring is still slightly offset), 2 - horizontal beam shift is observed, 3 - the tilt of the pattern indicated the presence of the beam astigmatism. 

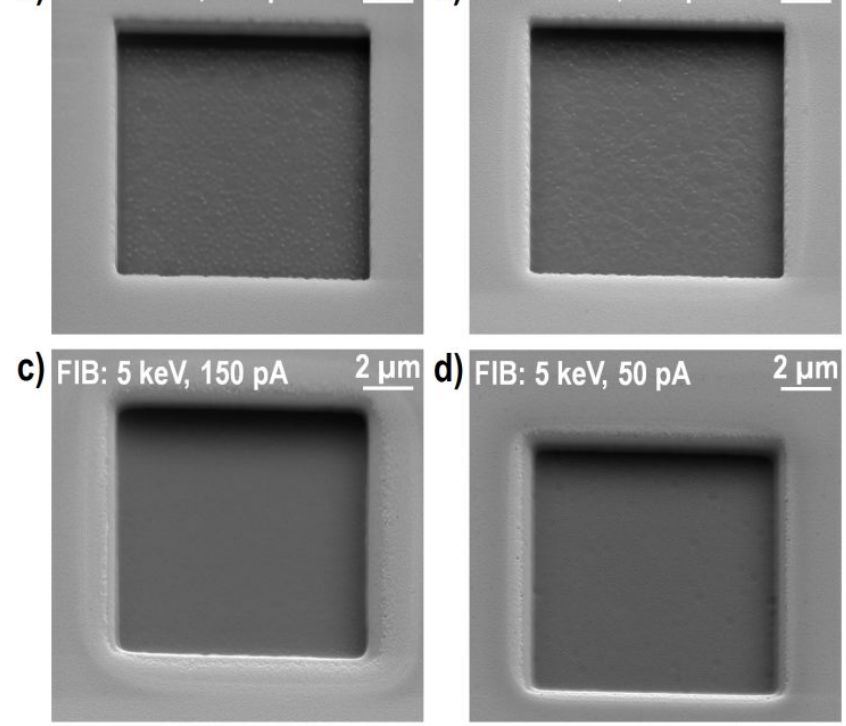

Figure S3. SEM images of post-FIB-TOF-SIMS craters obtained at different FIB energies and currents.

a)

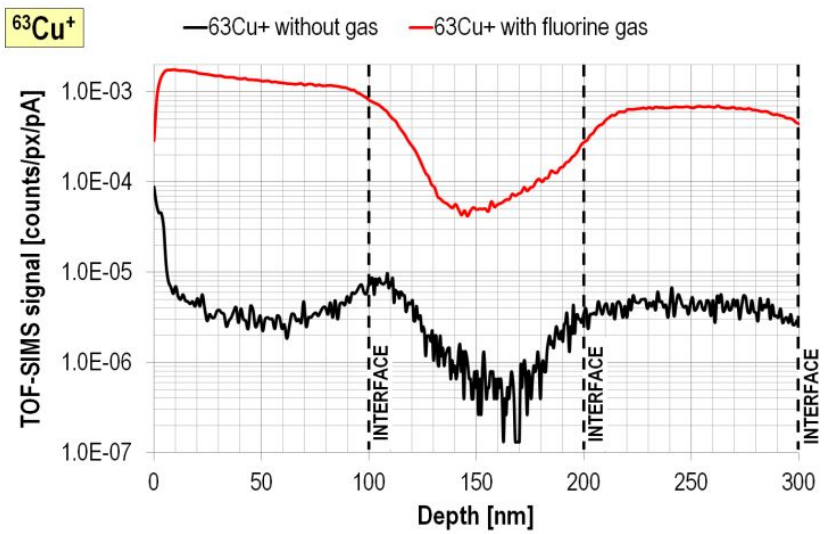

C) ${ }^{107} \mathrm{Ag}^{+} \quad-107 \mathrm{Ag}+$ without gas $\quad-107 \mathrm{Ag}+$ with fluorine gas

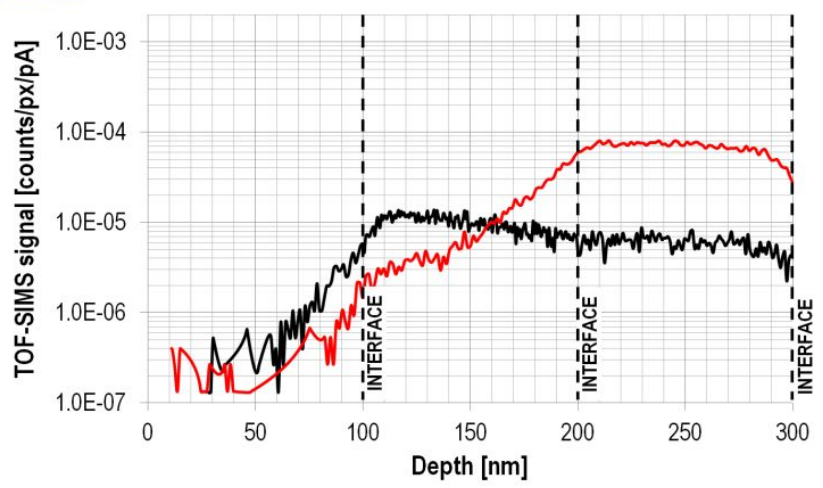

b)

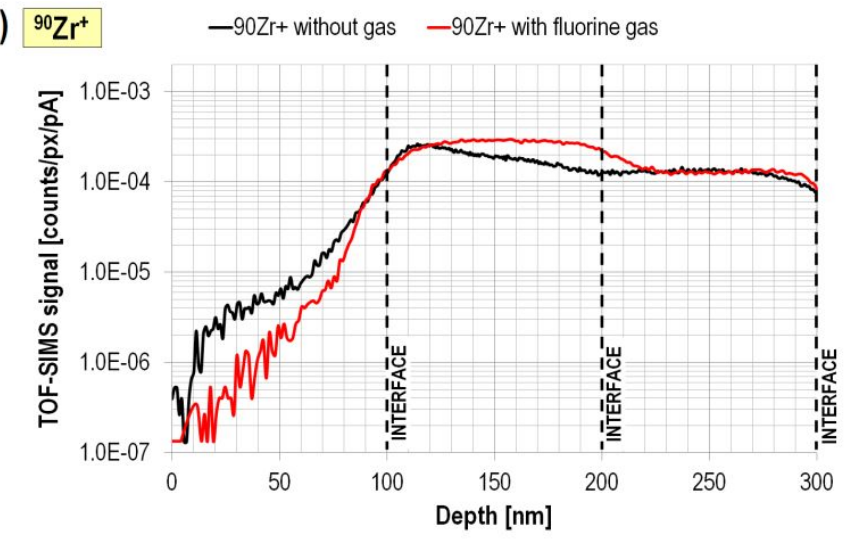

d) ${ }^{28} \mathrm{Si}^{+} \quad-28 \mathrm{Si}+$ without gas $-28 \mathrm{Si}+$ with fluorine gas

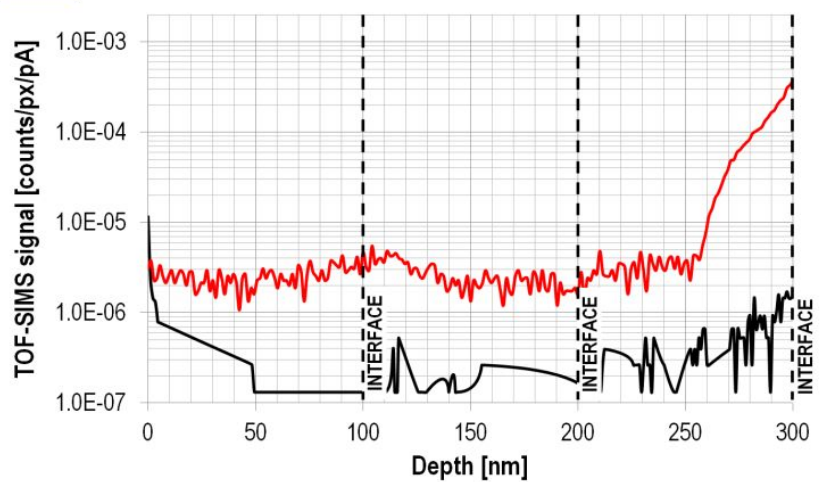

Figure S4. Comparison of the sample components' depth profiles obtained without (black lines) and with (red lines) the presence of fluorine gas. The $x$-scale was recalculated to depth units given in $\mathrm{nm}$ based on the interface recognition obtained from Figure 2. Note the logarithmic scale. 


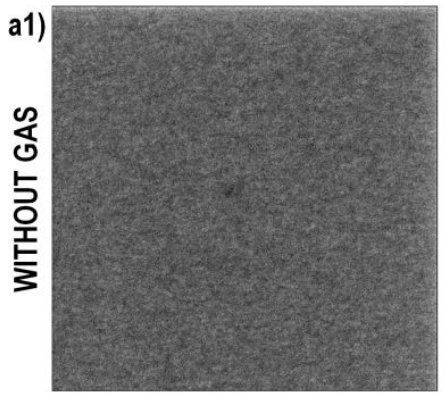

Sample surface

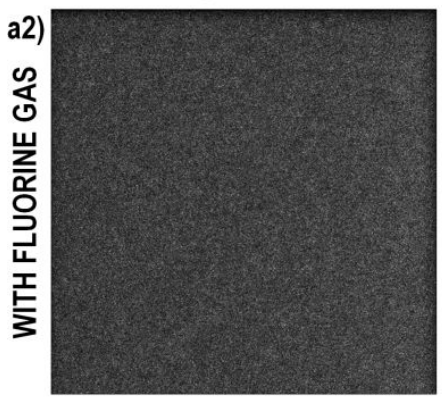

Sample surface

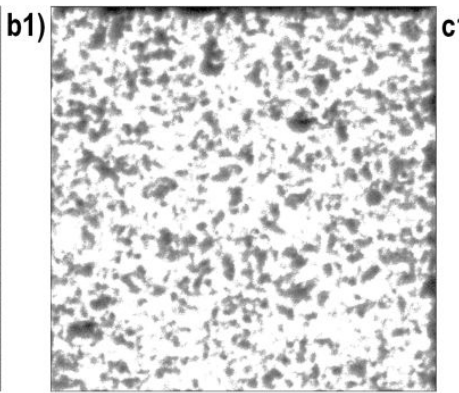

Cu-Zr interface

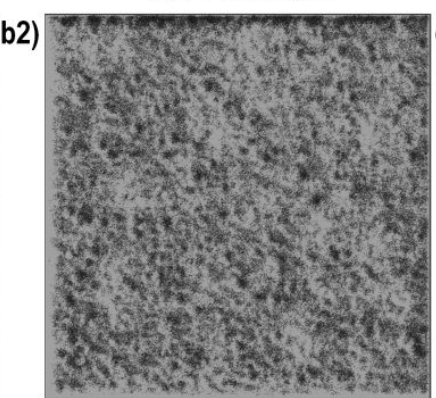

Cu-Zr interface

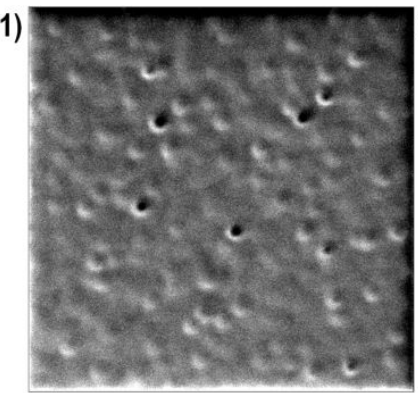

$\mathrm{Zr}$-ZrCuAg interface

c2)

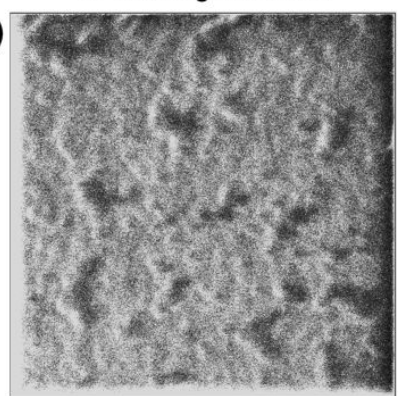

Zr-ZrCuAg interface

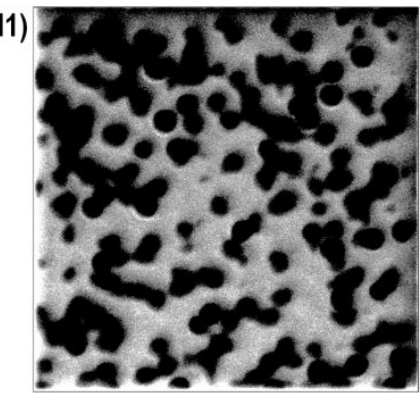

ZrCuAg-Si interface

d2)

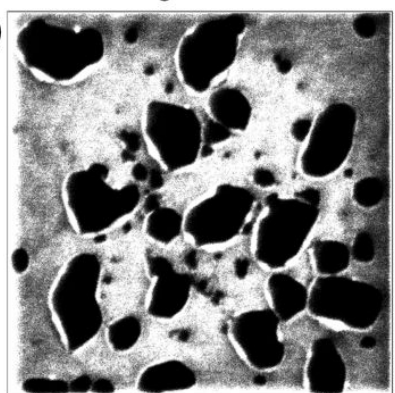

ZrCuAg-Si interface

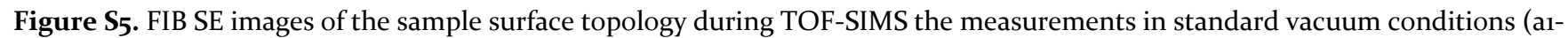
$\mathrm{a} 4)$ and with the presence of fluorine gas (az-d2).

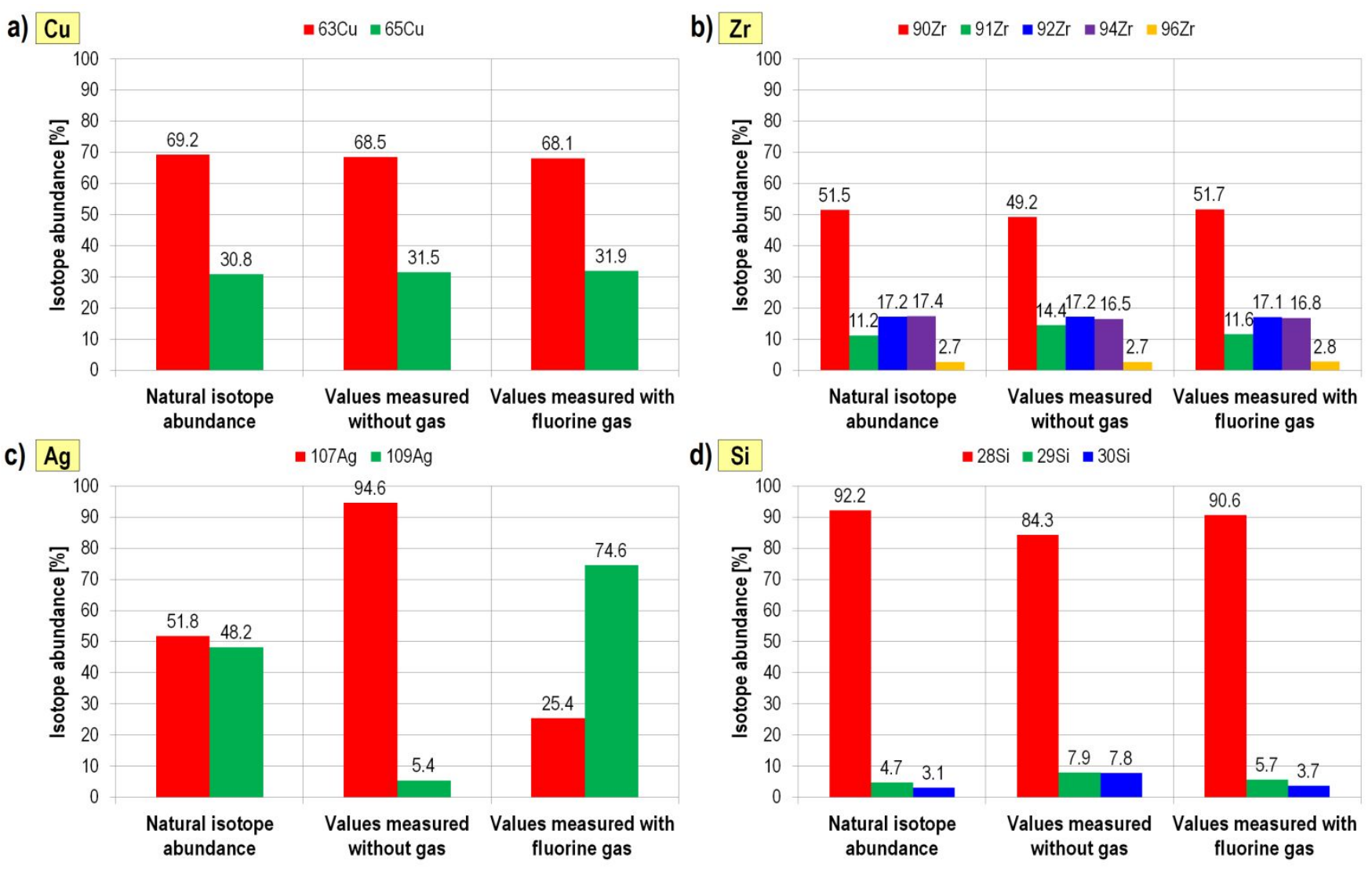

Figure S6. Isotope abundance of $\mathrm{Cu}(\mathrm{a}), \mathrm{Zr}(\mathrm{b}), \mathrm{Ag}(\mathrm{c})$ and $\mathrm{Si}(\mathrm{d})$. The measured values obtained using TOF-SIMS without and with the fluorine gas assistance are compared to the natural abundance of corresponding isotopes. 


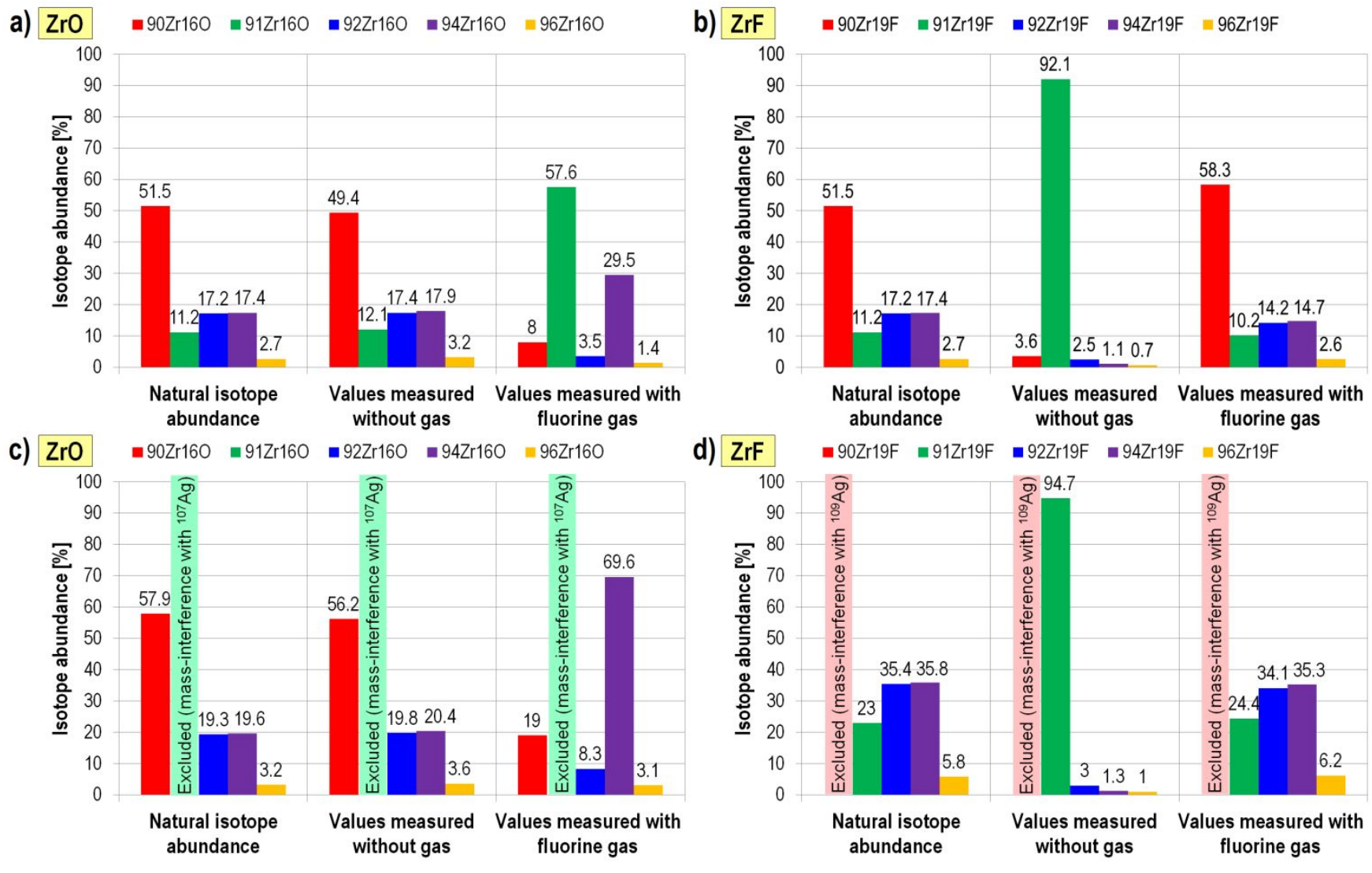

Figure $\mathrm{S}_{7}$. Comparison of $\mathrm{ZrO}$ and $\mathrm{ZrF}$ isotope abundance. It is assumed that the natural isotope of oxides and fluorides is the same as for pure elements. Description in the text. 